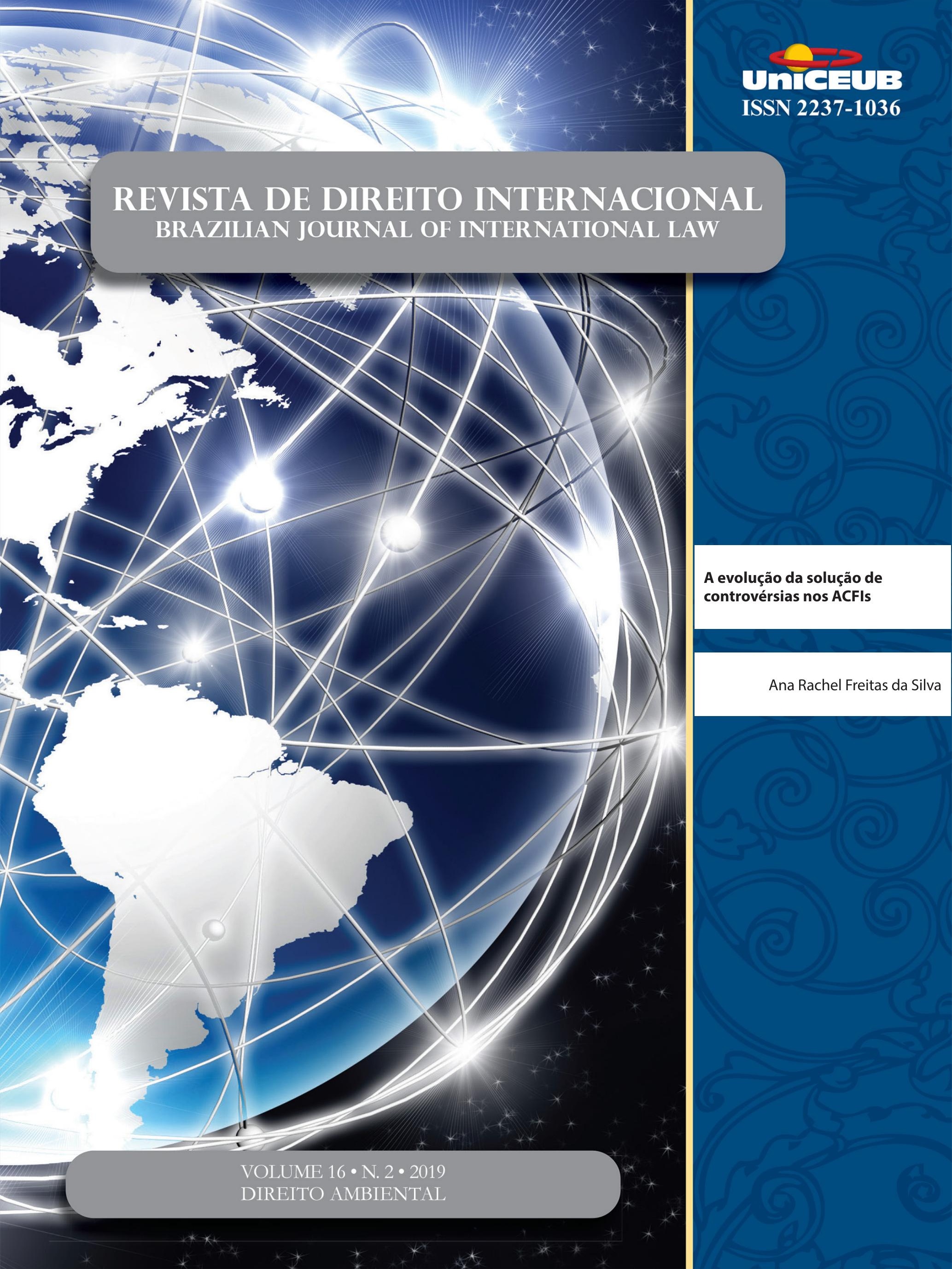




\section{Sumário}

I. Crônicas do Direito Internacional .................................................1

AMAZONIE: LE DROIT INTERNATIONAL EN VIGUEUR APPORTE DES RÉPONSES SUBSTANTIELLES ... 3 Pierre-Marie Dupuy

A eVOluÇão da SOluÇão DE CONTROVÉRSias NOS ACFIs 8 Ana Rachel Freitas da Silva

II. Dossiê Especial: Direito ambientai 14

A brief overview of Sustainable DeVelopment: HOW A DEBATEd CONCEPT With A MUCH-CONTESTED LEGAL NATURE COULD PERFORM A VALUABLE ROLE IN THE DECISION-MAKING ......16 Natali Francine Cinelli Moreira

A meta 11 de Aichi e as Áreas marinhas protegidas em grande ESCALA: proteção ambienTAL OU OPORTUNISMO POLÍTICO?

Alexandre Pereira da Silva

LITIGÂNCIA CLIMÁTICA COMO ESTRATÉGIA JURISDICIONAL AO AQUECIMENTO GLOBAL ANTROPOGÊNICO E MUDANÇAS CLIMÁTICAS

Délton Winter de Carvalho e Kelly de Souza Barbosa

AsSESSMENT AND CHALlENGES OF CARBON MARKETS

Louise Pigeolet e Arnaud Van Waeyenberge

As abordagens dos países da América Latina e Caribe sobre a mobilidade humana proVOCADA PELAS MUDANÇAS CLIMÁTICAS

Diogo Andreola Serraglio e Heline Sivini Ferreira

Implementation of Legal mechanisms of environmental protection by the South PaCIFIC REGIONAL ORGANIZATIONS 116 Joanna Siekiera 
CONCILIATING THE OVERLAP OF PROTECTED AREAS AND TRADITIONAL TERRITORIES: LEGAL INNOVATIONS FOR BIOLOGICAL DIVERSITY CONSERVATION IN BRAZILIAN PARKS

Nathalia Fernandes Lima e Solange Teles Silva

O USO DE DRONES COMO INSTRUMENTO PARA A CONSERVAÇÃo DA BIODIVERSIDADE NO BRASIL141 Larissa Suassuna Carvalho Barros e Marcia Dieguez Leuzinger

Agrotóxicos e direitos humanos no contexto global: o Brasil EM Risco de Retrocesso?

Marcelo Pretto Mosmann, Letícia Albuquerque e Isabele Bruna Barbieri

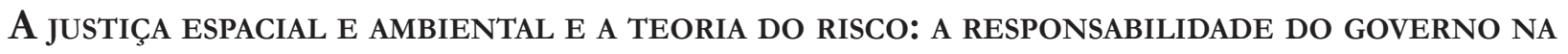
PREVENÇÃo CONTRA DESASTRES (NO BRASIL). 169

José Adércio Leite Sampaio e Edson Rodrigues de Oliveira

The judgment of the case Xucuru People v. Brazil: Inter-American Court of Human RigHTS BETWEEN CONSOLIDATION AND SETBACKS

Gabriela Cristina Braga Navarro

II. Artigos sobre outros temas

NACIONALIDADE: NOVAS REGRAS, VELHOS PROBLEMAS

226

Paulo Henrique Faria Nunes

O EXERCíCIO DA JURISDIÇÃO INTERAMERICANA DE DIREITOS HUMANOS: LEGITIMIDADE, PROBLEMAS E POSSÍVEIS SOLUÇÕES

Felipe Grizotto Ferreira, Guilherme Perez Cabrale Lucas Catib de Laurentiis

A proteção da identidade de gênero na jurisprudênCia da Corte Europeia de Direitos Humanos

Gabriel Coutinho Galil

O COMITÊ JURÍdico INTERAMERICANO dA OEA E A CODIFICAÇÃo DO DIREITO INTERNACIONAL REGIONAL. 
O caso Petruhhin e o princípio do nível mais elevado de proteção no tocante aos diREITOS FUNDAMENTAIS NO ÂMBITO DA UNIÃo EUROPEIA............................................304

Clovis Demarchi e Jaine Cristina Suzin

A AUTONOMia da VONTADE NA ESCOLHA dA LEI APLICÁVEl AOS CONTRATOS DE COMÉRCiO INTER-

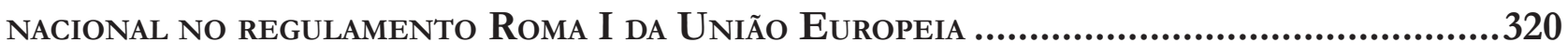

Aline Beltrame de Moura e Rafaela Hörmann

A JuRisdição da ICANN: desafios atuais e Prospectivas futuras...............................335 Aziz Tuffi Saliba e Amael Notini Moreira Bahia

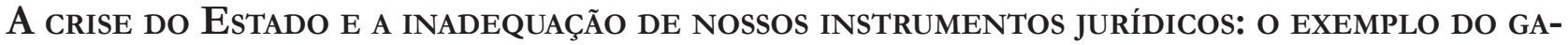
RANTISMO PENAL NO BRASIL.

Oswaldo Poll Costa e Francisco Quintanilha Veras Neto

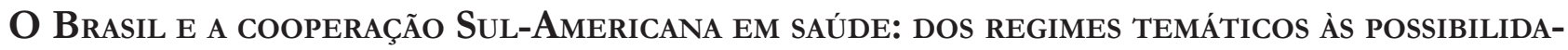
DES DE EFETIVAÇÃo ESTRUTURANTE

Ademar Pozzatti Junior e Luiza Witzel Farias

III. RESENHAS

Resenha da obra: SILVA, Waldimeiry Correa da. Regime internacional de enfrentaMENTO AO TRÁFICO DE PESSOAS: AVANÇOS E DESAFIOS PARA A PROTEÇÃo DOS DIREITOS HUMANOS. Rio de Janeiro: Lumen Juris, 2018. 385

Mércia Cardoso de Souza e Guirino Nhatave 


\title{
A evolução da solução de controvérsias nos ACFIs
}

\author{
Ana Rachel Freitas da Silva*
}

Um acordo de promoção e proteção de investimentos (APPI), nos moldes tradicionais, pode ser comparado a um acordo pré-nupcial, onde as partes já acordam os detalhes em caso de eventual divórcio, enquanto um acordo de cooperação e facilitação de investimentos (ACFI) pode ser melhor comparado a uma terapia de casal, já que foca na prevenção de conflitos para a manutenção da relação.

Não me lembro quem originalmente fez essa analogia, mas ela se tornou útil para explicar aos parceiros brasileiros sobre que bases o ACFI foi construído. E nesse processo de negociação, as preocupações, fruto da experiência nem sempre positiva dos vários países com os quais o Brasil tem negociado, vão tornando as disposições sobre soluções de controvérsias cada vez mais complexas. Um ACFI vai se aproximando, cada vez mais, de um APPI.

A presente crônica convida à reflexão sobre a evolução histórica da solução de controvérsias nos ACFIs, pontuando inovações e dificuldades no caminho seguido pelo Brasil. Tem-se por premissa, que o modelo brasileiro se torna, a cada negociação, um modelo multilateral e já representa uma proposta alternativa num contexto em que se discutem reformas à arbitragem investidor-Estado.

Por outro lado, a ampliação das negociações, uma possível reaproximação diplomática de países desenvolvidos, somadas à popularização da arbitragem envolvendo entidades estatais, podem provocar uma reviravolta na postura histórica brasileira de rejeição à arbitragem investidor-Estado. A reflexão sobre o tema, incluindo as premissas que justificaram a opção contrária a esse tipo de arbitragem, é essencial para que o país esteja preparado para enfrentar os desafios que se desenham.

O texto adota uma perspectiva cronológica. Inicia com apontamentos sobre a postura brasileira antes das negociações dos ACFIs. Segue considerando as modificações mais relevantes no modelo de solução de controvérsia desde a assinatura do primeiro ACFI com Moçambique até o ACFI assinado entre Brasil e Guiana em 13 de dezembro de $2018^{1}$. Conclui questionando o leitor sobre a in(evitável) aceitação da arbitragem investidor-Estado pelo Brasil.

\section{Os antecedentes}

A postura brasileira em relação aos acordos de investimentos sempre foi considerada peculiar. O país não ratificou nenhum dos 14 APPIs e 2 proto-

* Doutora em Direito pelo Centro Universitário de Brasília. Procuradora da Fazenda Nacional responsável pelo acompanhamento das negociações de acordos de investimentos pelo Brasil.E-mal: anarachel.freitas@gmail.com

\footnotetext{
São considerados para fins do presente estudo, os ACFIs celebrados pelo Brasil com Moçambique, Angola, Malauí, México, Colômbia, Chile, Etiópia, Suriname, Guiana, o capítulo de investimentos Acordo de Ampliação Econômico Comercial (AAEC) celebrado com Peru e o Protocolo de Investimentos do Mercosul. Os textos dos acordos mencionados, com exceção do ACFI com a Guiana que ainda não foi publicado, podem ser acessados no sítio eletrônico da UNCTAD: https://investmentpolicyhub.unctad.org/IIA/CountryBits/27\#iiaInnerMenu.
} 
colos no âmbito do Mercosul firmados na década de 90, nem é signatário da Convenção de Washington que criou o Centro de Solução de Diferendos Internacionais em Matéria de Investimentos (ICSID) ${ }^{2}$. Apesar disso, o Brasil seguiu como um importante receptor de investimento estrangeiro direto, alcançando o $5^{\circ}$ lugar em $2010^{3}$.

Dificuldades na aprovação dos acordos no Congresso Nacional provocaram sua retirada de pauta do legislativo e a constituição de um grupo de trabalho no âmbito da Câmara de Comércio Exterior (CAMEX) para elaboração de diretrizes que pudessem ser adotadas nas negociações de acordos de investimentos pelo Brasi $1^{4}$. Tais diretrizes levaram em conta as resistências enfrentadas na tramitação dos APPIs. Era necessário não apenas que o acordo fosse aceito pela outra parte, mas que pudesse ser referendado pelo legislativo. Para alcançar esses objetivos, as negociações foram iniciadas com países em desenvolvimento e o texto apresentado deixou de lado temas polêmicos como arbitragem investidor-Estado, desapropriação indireta, proteção do investimento de portfólio, para citar alguns exemplos.

O modelo brasileiro se assenta em três pilares principais: a) cooperação e facilitação de investimentos; b) Governança Institucional por órgãos permanentes e c) mitigação de riscos, prevenção e solução de controvérsias $^{5}$. Nesse momento, nos interessa mais de perto o último pilar: prevenção e solução de controvérsias.

\section{As três gerações de ACFIs}

Para tratar da evolução histórica dos ACFIs, optamos por dividi-los em três gerações e questionar se o

\footnotetext{
2 Sobre a resistência brasileira em firmar acordos de investimentos e participar do ICSID ver KALICKI, Jean; MEDEIROS, Suzana. Investment Arbitration in Brazil: Revisiting Brazil's Traditional Reluctance Towards ICSID, BITs and Investor-State Arbitration. Revista de Arbitragem e Mediação, vol. 14, n. 4, 2007, p. 57- 86.

3 Dados disponíveis no sítio eletrônico da Organização das Nações Unidas sobre Comércio e desenvolvimento: UNCTAD. World Investment Report 2011: non-equity modes of international production and development [online]. Genebra: UN Publications, 2011 [acesso em 28 de março de 2014]. Disponível em: <http:// unctad.org/en/PublicationsLibrary/wir2011_en.pdf>

4 BADIN, Michele Ratton Sanches e MOROSINI, Fabio. Navigation between Resistance and Conformity with the IIR. In: BADIN, Michele Ratton Sanches e MOROSINI, Fabio. Reconceptualizing International Investment Law for Global South. Cambridge: Cambridge University Press, 2018, p. 218-250.

5 Idem.
}

Brasil estaria preparado para uma quarta geração, com uma possível inclusão de arbitragem investidor-Estado. A primeira geração engloba os três primeiros ACFIs, firmados com Angola, Moçambique e Malauí. A segunda geração abarca os ACFIs celebrados com países da América Latina, como o México, Colômbia, Chile e Peru. A terceira geração se distingue da segunda, não por conta das disposições referentes à solução de controvérsias. O Protocolo Mercosul exemplifica essa terceira geração. Após a negociação que ocorreu com a Índia, cujo acordo ainda não foi assinado, a definição de investimento deixa de ser construída a partir do conceito de ativo para focar no conceito de empresa. Além disso, a cláusula sobre tratamento passa a se referir ao direito costumeiro, se aproximando de standards de tratamento mínimo internacional e a linguagem do acordo é mais incisiva quanto às obrigações dos investidores e não apenas se refere a melhores esforços. Fazemos o registro das três gerações, mas por tratarmos especificamente sobre solução de controvérsias, examinaremos a segunda e terceira gerações em conjunto nesse texto.

Os acordos da primeira geração foram negociados mais ou menos no mesmo período com parceiros africanos. Se constata uma prevalência de elementos de cooperação, sem maiores detalhes sobre a solução de controvérsias. Os artigos sobre prevenção de controvérsias, que indicam a presença de um ponto focal e a submissão de controvérsias aos Comitês Conjuntos tiveram poucas alterações desde 2015. O modelo brasileiro dá prevalência às instâncias de prevenção em detrimento das de solução de controvérsias ${ }^{6}$. A governança do acordo por esses órgãos e sua atuação na prevenção de controvérsias podem ser considerados como diferenciais do ACFI. Os acordos de primeira geração preveem, de forma genérica, a arbitragem entre Estados, sem trazer qualquer regra sobre composição do tribunal, o procedimento, dentre outros assuntos normalmente presentes em uma cláusula arbitral.

Os acordos de primeira geração trazem, em um único artigo, disposições sobre prevenção e solução de controvérsias. Entende-se que a prevenção é feita pelos Pontos Focais e pelo Comitê Conjunto. De fato, os pontos focais atuam no dia-a-dia do investidor, facili-

\footnotetext{
6 MONEBHURRUN, Nitish. Novelty in International Investment Law: The Brazilian Agreement on Cooperation and Facilitation of Investments as a Different International Investment Agreement Model. Journal of International Dispute Settlement. Vol. 8, 2017, p. $79-100$.
} 
tando o diálogo com os órgãos governamentais e oferecendo informação?

A atuação do Comitê Conjunto, por outro lado, em que pese ser uma condição prévia à instauração de um procedimento arbitral, em geral, se inicia quando já existe um conflito entre investidor e Estado. Entretanto, ainda que não seja "preventiva" em todos os casos, se apresenta como uma oportunidade para uma solução conciliatória, já que uma decisão do Comitê pressupõe a aquiescência de ambos os Estados envolvidos - o Estado anfitrião e o Estado de nacionalidade do investidor. Pode não prevenir uma controvérsia, mas previne uma arbitragem entre Estados.

As disposições sobre o Ponto Focal e o Comitê Conjunto praticamente se mantiveram nas gerações seguintes. As novidades aparecem no detalhamento da arbitragem Estado-Estado. A experiência dos países latino-americanos, bem como o envolvimento de equipes jurídicas nas negociações, contribuíram para tornar as disposições sobre arbitragem mais complexas.

Os acordos de segunda geração são aqueles firmados com países latino-americanos (com exceção do Protocolo do Mercosul e do acordo com a Guiana). Abrangem os ACFIs com México, Colômbia, Chile, o capítulo de investimentos do Acordo de Ampliação Econômico-Comercial entre Brasil e Peru. Os acordos com Etiópia e Suriname, apesar de assinados recentemente, também podem ser considerados como de segunda geração já que as negociações aconteceram a partir de um modelo elaborado quando da negociação com os países latino-americanos.

É interessante observar que primeiro parágrafo do artigo 19 do ACFI entre Brasil e México, menciona que o objetivo da arbitragem entre Estados é "colocar a medida em conformidade". Essa construção se repete em todos os ACFIs e se inspira no modelo OMC, bem conhecido e manejado pelo Brasil. O art. 19 (1) do Anexo II do Acordo Constitutivo da OMC estabelece que "quando um grupo especial ou Órgão de Apelação concluir que uma medida é incompatível com um acordo abrangido, deverá recomendar que o Membro inte-

\footnotetext{
Ao Ponto Focal cabe, entre outros: "interagir com as autoridades governamentais competentes para avaliar e recomendar, quando adequado, o devido tratamento para as sugestões e reclamações recebidas dos governos e investidores da outra Parte", "prestar informações tempestivas e úteis às Partes sobre questões normativas relacionadas a investimentos em geral ou a projetos específicos". (art. $5^{\circ}$ do ACFI Brasil-Angola.).
}

ressado torne a medida compatível com o acordo" ${ }^{\text {. No }}$ mesmo sentido, o acordo 3.7 demonstra a preferência pela retirada da medida considerada desconforme em detrimento de uma decisão pela compensação.

O mandato dos árbitros no ACFI é bem distinto dos tradicionais APPIs, onde o investidor prejudicado busca uma compensação em face do Estado anfitrião ${ }^{10}$. No ACFI, uma decisão pela compensação necessitaria de um consentimento adicional por parte dos Estados ${ }^{11}$. A compensação poderia ser útil, por exemplo, quando não há interesse do Estado de rever uma medida de amplo alcance como um caso de violação ao tratamento nacional. Em outras situações, como desapropriações e perdas decorrentes de guerras, por exemplo, a decisão do tribunal implicará, em última instância, numa obrigação de pagamento. Tornar compatível uma desapropriação sem pagamento nos termos do tratado significa fazer o pagamento ou restituir a propriedade.

A princípio, uma decisão arbitral autorizada pelo ACFI se limitaria a constatar que uma das Partes está descumprindo o acordo, sem prever como tal decisão será cumprida. O ACFI celebrado com a Colômbia especifica que "a decisão do Tribunal Arbitral será definitiva e obrigatória para as Partes, que deverão cumpri-la sem demora" 12 , Contudo, diferentemente do sistema

8 O Acordo Constitutivo da OMC, incluindo seu anexo II que dispõe sobre o Entendimento Relativo às Normas e Procedimentos sobre Solução de Controvérsias foi promulgada pelo Decreto $\mathrm{n}^{\circ}$ 1.355, de 30 de dezembro de 1994. Disponível em: < http://www. planalto.gov.br/ccivil_03/decreto/Antigos/D1355.htm>. Acesso em 2 de janeiro de 2019.

9 “(...) Na impossibilidade de uma solução mutuamente acordada, o primeiro objetivo do mecanismo de solução de controvérsias será geralmente de conseguir a supressão das medidas de que se trata, caso se verifique que estas são incompatíveis com as disposições de qualquer dos acordos abrangidos. Não se deverá recorrer à compensação a não ser nos casos em que não seja factível a supressão dessas medidas. O último recurso previsto no presente Entendimento para o Membro que invoque os procedimentos de solução de controvérsias é a possiblidade de suspender, de maneira discriminatória contra o outro Membro, a aplicação de concessões ou o cumprimento de outras obrigações no âmbito dos acordos abrangidos, caso o OSC autorize a adoção de tais medidas. (Disponível em: <http://www. planalto.gov.br/ccivil_03/decreto/Antigos/D1355.htm>. Acesso em 2 de janeiro de 2019.)

10 VIDIGAL, Geraldo; STEVENS, Beatriz. Brazil's New Model of Dispute Settlement for

Investment: Return to the Past or Alternative for the Future?. Journal of World Investment and Trade, n.19. 2018, pp. 475-512. .

11 Art. 19(2) do ACFI com México, art. 23 (14) do ACFI com Colômbia, art. 25 (13) do ACFI com Suriname e art. 24 (11) do ACFI com a Etiópia.

12 Artigo 23(12). 
OMC, que prevê a adoção de retaliações com objetivo de "convencer" o Estado recalcitrante a modificar a medida condenada ${ }^{13}$, eventual decisão arbitral no ACFI seria de difícil execução se não cumprida voluntariamente ${ }^{14}$.

De fato, o país estaria descumprindo uma decisão internacional e poderia sofrer danos reputacionais ${ }^{15}$. Poder-se-ia, até mesmo, pensar em uma execução de sentença arbitral nos termos da Convenção de Nova York $^{16}$, mas tal ação esbarraria na dificuldade de liquidação da sentença já que o próprio acordo não estabelece como seria feito. Eventual conversão de uma decisão de "colocar a medida em conformidade" em compensação por danos parece exorbitar a competência arbitral, salvo se autorizado pelas Partes. Por outro lado, uma sentença que reconhece a ilicitude da conduta do Estado anfitrião poderia ser utilizada pelo investidor prejudicado, como elemento de prova em um processo de conhecimento nas cortes domésticas.

A arbitragem entre Estados não é uma grande novidade. Alguns acordos já contemplam arbitragem entre Estados para fins de interpretação do tratado. O modelo americano de 2012, por exemplo, contém duas sessões. A sessão A (artigos 23 a 36) aplica-se à arbitragem iniciada pelo investidor, enquanto a sessão B (artigo 37) autoriza a arbitragem entre Estados "relativas à interpretação ou aplicação do tratado" 1718 . Observa-se que a arbitragem entre Estados, nesses acordos, tem por escopo a interpretação do tratado. Essa interpretação até

13 Ver artigo 22 do anexo II do Acordo Constitutivo da OMC.

14 Nos referimos aqui a uma arbitragem que julgue apenas se a medida está em conformidade com o ACFI. Eventual decisão que estabeleça uma compensação para o investidor prejudicado pela medida será tratada a seguir.

15 SILVA, Ana Rachel Freitas. Estados e investidores estrangeiros: é possível alcançar cooperação? Revista Direito GV, v. 13, n. 1, mai. 2017, p. 123-144.

16 Convenção sobre o Reconhecimento e Execução de Sentenças Arbitrais Estrangeiras, firmada em 10 de junho de 1958, internalizada no ordenamento jurídico brasileiro pelo Decreto $\mathrm{n}^{\circ} 4.311$, de 23 de julho de 2002. Disponível em: < http:/ /www.planalto.gov.br/ ccivil_03/decreto/2002/D4311.htm>.Acesso em 2 de janeiro de 2019.

172012 U.S. Model Bilateral Investment Treaty (Disponível em https://investmentpolicyhub.unctad.org/Download/TreatyFile/2870), acesso em 29 de dezembro de 2018.

18 No mesmo sentido o tratado modelo da Alemanha, de 2008 (disponível em: https://investmentpolicyhub.unctad.org/Download/TreatyFile/2865); o modelo francês (disponível em: https:// investmentpolicyhub.unctad.org/Download/TreatyFile/2862), o acordo modelo do Canadá, de 2004(disponível em: https://investmentpolicyhub.unctad.org/Download/TreatyFile/2820). pode ter efeitos em um caso específico, mas em geral tem escopo mais amplo e prospectivo ${ }^{19}$.

Essa fórmula acabou sendo utilizada no ACFI com o Chile ${ }^{20}$.Contudo, na prática, o escopo da arbitragem entre Estados nesse acordo não deve ser diferente dos demais ACFIs já que, consoante o art. $3^{\circ}$, constará dos termos de referência que os árbitros determinarão "de forma fundamentada se a medida em questão está ou não em conformidade com o Acordo".

Os ACFIs celebrados com México, Colômbia, Suriname, Etiópia permitem uma espécie de arbitragem de compensação. O ACFI celebrado com o Chile, além do AAEC entre Brasil e Peru e o Protocolo do MERCOSUL não trazem essa previsão, o que não impede que os Estados celebrem um compromisso arbitral nesse sentido. Além disso, as disposições sobre nação mais favorecida dos acordos de primeira geração, já que não excluem expressamente de seus escopos a solução de controvérsias, poderiam estender àqueles países as condições ofertadas nos ACFIs de segunda geração ${ }^{21}$.

A previsão do ACFI de uma arbitragem iniciada pelo Estado de nacionalidade do investidor, que avalie os danos sofridos por este último, tem um escopo bem diferente da interpretação do tratado. O dispositivo mencionado regula a relação disciplinada pelas regras de direito consuetudinário relativas à proteção diplomática. Baseia-se na ficção de que um dano causado a um nacional de determinado Estado pode ser considerado um dano causado ao próprio Estado ${ }^{22}$. Conforme conceituado pelos artigos elaborados pela Comissão de Direito Internacional da ONU sobre Proteção Diplomática:

proteção diplomática consiste na invocação por

19 Sobre a arbitragem Estado-Estado nos APPIs ver: ROBERTS, Anthea. State-to-State Investment Treaty Arbitration: a Hybrid Theory of Interdependent Rights and Shared Interpretative Authority. Harvard International Law Journal, vol. 55, n. 4, 2014. Disponível em: < http://www.harvardili.org/wp-content/uploads/Roberts. pdf $>$. Acesso em 6 de outubro de 2018.

${ }^{20} \mathrm{O}$ art. 1(1) do Anexo I, dispõe que "as controvérsias que surjam entre as Partes com relação à interpretação ou aplicação das disposições contidas neste Acordo poderão ser submetidas ao procedimento de arbitragem estabelecido neste Anexo",

${ }^{21}$ BERNASCONI-OSTERWALDER, Nathalie e BRAUCH, Martin Dietrich. Comparative Commentary to Brazil's Cooperation and Investment Facilitation Agreements (CIFAs) with Mozambique, Angola, Mexico, and Malawi. Sep. 2015. Disponível em: < https:// www.iisd.org/sites/default/files/publications/commentary-brazilcifas-acfis-mozambique-angola-mexico-malawi.pdf $>$. Acesso em 30 de dezembro de 2018.

22 VATEL apud BROWLIE, Ian. Principles of Public International Law. $4^{\text {th }}$ ed. Oxford: Claredon Press, 1990, p. 518 
um Estado, por ação diplomática ou outros meios pacíficos de resolução, da responsabilidade de um outro Estado por um dano causado por um ato ilícito internacional deste último a uma pessoa natural ou jurídica do primeiro Estado, com o objetivo de implementar dita responsabilidade. ${ }^{23}$

O artigos elaborados pela Comissão de Direito Internacional buscam consolidar normas costumeiras que governam essas relações. Nesse ponto, questiona-se a interação entre as fontes de direito aplicáveis. Por um lado, as regras costumeiras da proteção diplomática exigiriam o esgotamento dos recursos internos ${ }^{24}$. Por outro lado, o próprio tratado firmado entre as Partes não traz essa condição, mas exige, por exemplo, que a controvérsia seja discutida no âmbito do Comitê Conjunto, respeite o prazo prescricional de 5 anos e que haja a desistência de ações em curso nas Cortes Locais ${ }^{25}$.

Parece que na relação entre tratado e o costume, o tratado seria mais específico, trazendo de forma expressa a vontade das partes. Apesar da decisão da Corte Internacional de Justiça, pela não presunção de renúncia tácita do esgotamento dos recursos internos ${ }^{26}$, poder-se-ia questionar, tendo por base o texto do ACFI, se não houve a renúncia, ao incluir expressamente condições outras que não a mencionada ${ }^{27}$.Além disso, os artigos que tratam da compensação do investidor, exigem que este renuncie à sua reclamação perante as cortes locais ou tribunais arbitrais do Estado anfitrião $0^{28}$. Pela redação mencionada, o Estado de nacionalidade do investidor poderia iniciar uma arbitragem entre Estados ainda na pendência de uma ação do investidor e, portanto, seria incompatível a exigência de esgotamento de recursos internos.

A arbitragem compensatória, apesar de inspirada na proteção diplomática, tem regulamentação própria. Destaca-se a tentativa de impedir que o investidor pos-

\footnotetext{
23 Tradução livre do artigo 1. UN ILC. Draft Article on Diplomatic Protection with commentaries, 2006. Disponível em: http://legal. un.org/ilc/texts/instruments/english/commentaries/9_8_2006. pdf. Acesso em 7 de janeiro de 2019.

24 Art. 14 ILC Draft Articles on Diplomatic Protection.

25 Ver, por exemplo, art. 24 do ACFI celebrado com Etiópia.

26 CIJ. Case Concerning Elettronica Sicula S.P.A. (ELSI) Julgamento de 20 de julho de 1989, par. 50. Disponível em: < https://www. icj-cij.org/files / case-related/76/076-19890720-JUD-01-00-EN. pdf $>$. Acesso em 5 de janeiro de 2019.

${ }^{27}$ Por outro lado, a Corte Internacional de Justiça no Caso ELSI considerou que não se pressupunha a renúncia tácita do esgotamento dos recursos internos.

28 Ver, por exemplo art. 25(13) b do ACFI firmado entre Brasil e Suriname e art. 24(11) b do ACFI firmado entre Brasil e Etiópia.
}

sa auferir dupla indenização: via proteção diplomática e como autor perante cortes domésticas ou tribunais arbitrais do Estado anfitrião ${ }^{29}$. Ainda que versem sobre os mesmos fatos, eventuais ações movidas pelo investidor não se confundem com o objeto da arbitragem de compensação Estado-Estado. Em primeiro lugar porque não há identidade de partes. Uma ação iniciada por um Estado contra outro Estado tendo por base um tratado não se confunde com uma demanda iniciada por um investidor que discuta, por exemplo, uma desapropriação tendo por base a legislação doméstica. Talvez por essa razão o texto mencione a coincidência de uma "reclamação sobre a medida questionada no Comitê Conjunto" e não mencione litispendência. De qualquer sorte, será interessante observar a interpretação dada a essa disposição pelos tribunais.

\section{Uma quarta geração?}

Não há dúvidas que a possibilidade de iniciar uma arbitragem contra o Estado anfitrião sem o patrocínio do Estado de nacionalidade é a situação desejável para o investidor. Investidores brasileiros estariam mais protegidos se contassem com o consentimento para arbitragem do Estado parte no ACFI. Contudo, uma decisão nesse sentido, ademais de eventuais questionamentos de natureza jurídica que possam ser levantados, passa pelo sopesamento dos interesses ofensivos e defensivos do país. Repousa também, na análise de custos e benefícios dessa mudança de paradigma.

O modelo brasileiro não está imune a críticas. Trata-se de uma opção extremamente centralizada no Estado. Aliás, uma das críticas mais contundentes ao modelo é politização da questão. Essa politização não se resume à arbitragem Estado-Estado e a ausência da arbitragem investidor-Estado. Instâncias decisórias como o Ponto Focal, o Comitê Conjunto também são dependentes da atuação do Estado.

O Ponto Focal, por exemplo, funciona no Brasil na Câmara de Comércio Exterior ${ }^{30}$. Trata-se de órgão da

\footnotetext{
29 Art. 25 (13) b do ACFI com a Etiópia prevê:

30 Decreto $n^{\circ} 8.807$, de 2016, alterou o Decreto no 4.732, de 2003, para estabelecer a competência da Secretaria Executiva da CAMEX para desempenhar as funções de Ponto Focal-Ombudsman de Investimentos Diretos. Disponível em: < https://www.planalto.gov. br/ccivil_03/decreto/2003/D4732.htm>. Acesso m 2 de janeiro de 2019.
} 
estrutura governamental, sem independência para apreciar e resolver as reclamações apresentadas por investidores estrangeiros. Se houver engajamento do Estado, o Ponto Focal pode ter uma atuação importante, facilitando o acesso do investidor aos demais órgãos governamentais encarregados de políticas de investimentos ${ }^{31}$. Por outro lado, caso não haja o necessário compromisso estatal, os processos perante essa instância podem ser tornar apenas pro forma e ter pouco resultado prático. O investidor não teria outra instância para reclamar da ineficiência do ombudsman.

Tal preocupação pode ser estendida à atuação do Comitê Conjunto. Ainda que se possibilite a participação do setor privado em reuniões, a competência para decidir repousa, em última instância, nos Estados e o grau de cooperação das partes ficará evidente nos trabalhos do Comitê.

Muito se fala nos perigos em se conceder poder dos árbitros para avaliar as políticas estatais e interferir no exercício do poder regulatório dos Estados ${ }^{32}$. Aceitar arbitragem investidor-Estado não significa, por si só, que o Estado passa a ter que submeter seus interesses ao escrutínio de um grupo de árbitros privados. A arbitragem encontra por fundamento a vontade das partes ${ }^{33}$ e também está limitada a essa vontade. A arbitragem investidor-Estado não precisa ser vista como um tabu. A competência dos árbitros vai depender dos termos do consentimento estatal. Por isso a importância de se trabalhar em uma cláusula que dê conforto aos Estados signatários do tratado.

Por outro lado, o Brasil está numa posição confortável por ter conseguido se manter fora do sistema enquanto outros países enfrentavam arbitragens desfavoráveis, buscando, inclusive, uma saída de seus compromissos internacionais ${ }^{34}$. $\mathrm{O}$ fato de ser considerado

31 Em 20/12/2018, a CAMEX relatou as ações executadas na área de investimentos no ano de 2018. Disponível em: < http://www. camex.gov.br/destaque/2167-se-camex-apresenta-as-entregas-de2018-relacionadas-ao-tema-investimento $>$. Acesso em 7 de janeiro de 2019.

32 SORNARAJAH, M. Resistance and Change in the International Law on Foreign Investment. Cambridge: Cambridge University Press, 2015.

33 PAULSSON, Jan. The Idea of Arbitration. Oxford University Press: New York, 2013.

$34 \mathrm{Na}$ América Latina, por exemplo, vemos o caso de Bolívia, Equador e Venezuela que denunciaram a Convenção de Washington e Argentina que resistia, como podia, a execução de sentenças arbitrais. Sobre o tema: VINCENTELLI, Ignacio A. The Uncertain Future of ICSID in Latin America. Law and Business Review of the um destino atraente para o capital estrangeiro reforça essa posição. Não parece haver necessidade de uma corrida para a aceitação da arbitragem investidor-Estado. Ademais, o ACFI se consolidou como uma alternativa.

Essa aparente bonança não impede, entretanto, que o país possa explorar opções que possibilitem acesso direto aos investidores nacionais. O Brasil tem acompanhado de perto as discussões do Grupo de Trabalho III da UNCITRAL sobre reforma da solução de controvérsias investidor-Estado ${ }^{35}$. Dentre as propostas apresentadas destacamos a criação de um tribunal internacional de investimentos.

De qualquer forma, é mister reconhecer que o Brasil tem migrado de uma posição de expectador para participante mais ativo na tarefa de moldar o regime jurídico internacional de investimentos. Talvez esteja chegando o momento de dar um passo adiante e examinar as consequências de conceder direito de ação diretamente ao investidor, seja para um processo arbitral seja para um julgamento por um órgão internacional.

\section{Considerações finais}

O ACFI tem o mérito de apresentar uma alternativa ao modelo amplamente usado de acordos de investimentos com arbitragem investidor-Estado. Uma proposta construída a partir da cooperação e prevenção de disputas e que deu conforto ao Brasil para que pudesse deixar seu isolacionismo na área. Vencidas as resistências iniciais, o país está pronto para avançar, explorando, por exemplo, cenários em que se permita acesso direto ao investidor estrangeiro, optando pela arbitragem ou por um tribunal internacional. É tempo de investir, também, na solução de controvérsias e pensar quais seriam os melhores termos que deveriam constar de um acordo pré-nupcial de investimentos. Um bom acordo não prescinde de uma boa terapia e vice-versa.

Americas, vol. 16, n. 3, 2010, p. 409-456.

35 Relatórios das discussões podem ser acessados no sítio eletrônico da instituição: http://www.uncitral.org/uncitral/en/commission/working_groups/3Investor_State.html. 
Para publicar na Revista de Direito Internacional, acesse o endereço eletrônico www.rdi.uniceub.br ou www.brazilianjournal.org.

Observe as normas de publicação, para facilitar e agilizar o trabalho de edição. 